\title{
Virus, Immunity and Human Neurodegenerative Diseases. A Perspective
}

\section{Rodríguez-Leyva Ildefonso* and Jiménez-Capdeville María E}

School of Medicine, Universidad Autónoma De San Luis Potosí and Neurology

Department, Hospital Central "Dr. Ignacio Morones Prieto", San Luis Potosí, S.L.P.,

México

*Corresponding Author: Rodríguez-Leyva Ildefonso, School of Medicine, Universidad Autónoma De San Luis Potosí and Neurology Department, Hospital Central “Dr. Ignacio Morones Prieto", San Luis Potosí, S.L.P., México.

DOI: $10.31080 / A S M I .2020 .04 .0764$

A century ago, von Economo described a central nervous system (CNS) disorder related to an epidemic problem, presented from 1916 to 1927 . The principal affection was related to the midbrain and basal nuclei, whereby the patients showed neuropsychiatric manifestations, mainly Parkinsonism. Since then, the influenza virus was associated to these sequelae. Recently, it has been documented that Von Economo's working hypothesis was that the immune response could affect the neuronal function through antibodies, with lymphocytic infiltration of $\mathrm{B}$ and $\mathrm{T}$ cells in peri-venous localization [1]. The encephalitis that he described, also known as Encephalitis Lethargica (EL), had three different presentations: a) The somnolent-ophthalmoplegic type, characterized by malaise, headache, myalgia and fever. The progressive somnolence lead the patient to coma in one or two weeks, resulting in death in 50 percent of cases and in complete recovery in the remaining. Several patients had ptosis, diplopia and rigidity of the extremities, with somnolence periods, suggesting the name "sleepy sickness". b) The hyperkinetic presentation, characterized by restlessness, twitching or jerking muscles, severe neck and back pain, prostration with inversion of the sleep pattern and presence of chorea. Compared to the somnolent-ophtalmoplegic presentation, the hyperkinetic form had a more acute pattern and a lower mortality rate (40\%), but fewer possibilities of full recovery. c) The amyostatic-akinetic form, which was the least frequent, this was associated with chronic sequelae, and was designated by Von Economo as parkinsonism. This set of sequels seems remarkably similar to Parkinson's Disease, with similar affected sites but some differences: age of onset (anyone), tremor absence and faster evolution. Since then, there are multiple reports of EL related to viral encephalitis, not necessarily associated to influenza [2]. The presence of oligoclonal bands and the beneficial response to steroids suggested the idea that it could be an autoimmune disease, or it could have a similar phenotype to the postinfectious chorea (PANDAS). In postinfec-
Received: December 08, 2020

Published: January 22, 2021

(C) All rights are reserved by Rodríguez-Leyva Ildefonso* and Jiménez-Capdeville María E tious chorea (Sydenham chorea), the antistreptolysins are elevated. In EL, autoantibodies against human basal ganglia antigens are present, but with clear perivenous infiltration of B and Tymphocytes, specially affecting the striatum. The initial etiology could be related to influenza or neurotropic virus (herpes) and even a streptococcus bacteria, as a postinfectious autoimmune encephalitis [3]. The different clinical presentations could be attributed to the different topography of the affection, with sleep dysfunction, psychiatric symptoms and Parkinsonism (diencephalic, cortical and midbrain affection respectively) and specific manifestations as the RBD (REM behavior disorder) that could be related to damage to the peduncular pontine nucleus (PPN) [4].

From the beginning, it was clear that this Parkinsonism was definitively different from Parkinson's disease and from other degenerative Parkinsonisms. Nevertheless, the report of the presence of neurofibrillary tangles associated with neuronal loss and gliosis in the locus coeruleus, raphe nucleus, substantia nigra, frontal, temporal and occipital cortices in a patient with EL strongly suggest a further step from neuroinflammation to neurodegeneration, in light of the current knowledge [5]. One hundred years after this pandemic situation, the question remains about this intriguing disease: Etiology? Transmission? Awfully, the world is now facing a new pandemic situation, and the possibility of facing a similar neurological problem as a COVID-19 sequel, as the humanity confronted a century ago, is intimidating [6]. When the suspicion of something similar happening in this pandemic situation emerged, we found the publication of Badfarm and Zandifar (2020) formulating a similar hypothesis: could it be possible to see long term consequences with CNS affection after COVID-19? [7]. Concerning the possible CNS impact of this virus, there are reports of several patients affected in the encephalon supported by CSF data (hyperproteinorachia and pleocytosis), MRI (image suggesting ADEM, limbic affection or no apparent damage), with clinical manifestations of 
delirium, aphasia/dysarthria, and seizures [8]. It is important to emphasize that cases of encephalitis associated to COVID-19 presented even without clinical respiratory or digestive affection, as reported by Zambreanu and collaborators [9] and a COVID-19 associated encephalitis occurs at any age, similarly to EL [10]. There are also reports of diverse topography of the lesions, for instance Bickerstaff encephalitis (brainstem alteration) with cerebellar affection [11] and also limbic localization. Something that could be very intriguing is the presence of cross antibodies such anti-GAD [11] and anti-NMDAr [12,13], as it was reported for EL [3].

Until now, no specific treatment has been defined. Antinflammatory drugs, especially steroids, seem to be the main treatment for this process, suggesting that the core problem could be the immune reaction to the virus and the cross response in the affected [14]. Previous reports underlined the apparent relationship between viral encephalic affection and NMDA limbic encephalitis. This process starts with the viral infection, but a posterior secondary immunological process leads to the formation of antibodies against the NMDA receptor [15]. Furthermore, not only virus have been related to anti-NMDAr antibodies, also Mycoplasma pneumonie, besides a crossed response with ovarian tumors [16]. Therefore, a direct relationship between viral CNS infection and autoimmunity has been demonstrated through PCR for the virus and the presence of autoantibodies followed by secondary inflammation, as well as by the detailed description of an autoimmune postinfectious encephalitis [17].

The secondary damage associated with the presence of antiNMDAr has been linked to neurodegeneration [18]. In the same direction, the dynamic modification of the neuronal cytoskeleton has been related with viral infections, especially through herpes virus, with the formation of paired helical filaments (PFHs), one of the possible links to Alzheimer disease [19]. The neurodegenerative process can involve an underlying process between viral infection and autoimmunity as a cross response to the virus invasion. Both DNA virus (Herpes viridae family, JC virus), and RNA virus (Influenza, Measles, Rabies, West Nile, St. Louis, Polio, Echo, Coxsackie, Entero, and HIV) are neurotropic. All of them induce DNA modifications that could drive epigenetic changes leading to alterations of proteostasis. The formation of aggregates and inclusion bodies is associated to functional loss and neuronal death. The Epstein-Barr virus (EBV) and Varicella zoster virus (VZV) have been associated to multiple sclerosis (MS), H1N1 Influenza virus has been related to Parkinson Disease, HIV has been related to motoneuron disease, and the common underlying cause for all of them is the presence of the virus, secondary inflammation, immune activation and proteinopathy [20].

What is the perspective towards the post-pandemic era? It is difficult to make predictions, but it will be undoubtedly a new quest for researchers and physicians. Unfortunately, vaccines are not a universal solution, since we face many cases of cross-reaction, as it has happened with the influenza vaccine and ADEM, or the COVID vaccine itself and secondary transverse myelitis. A panorama has emerged that forces us to continue studying this intricate relationship between susceptibility, environment, viruses, inflammation, autoimmunity, and neurodegeneration, especially with a neurotropic virus as SARS-COV-2 [21].

\section{Bibliography}

1. Reid AH., et al. "Experimenting on the Past: The Enigma of von Economo's Encephalitis Lethargica”. Journal of Neuropathology and Experimental Neurology 60.7 (2001): 663-670.

2. Howard RS and Lees AJ. "Encephalitis lethargica: a report of four recent cases”. Brain 110.1 (1987): 19-33.

3. Dale R., et al. "Encephalitis lethargica syndrome: 20 New cases and evidence of basal ganglia autoimmunity". Brain Journal of Neurology 127 (2004): 21-33.

4. Lutters B., et al. "The centennial lesson of encephalitis lethargica". Neurology 90.12 (2018): 563.

5. Haraguchi T., et al. "An autopsy case of postencephalitic parkinsonism of von Economo type: some new observations concerning neurofibrillary tangles and astrocytic tangles". Neuropathology 20.2 (2000): 143-148.

6. Hoffman LA and Vilensky JA. "Encephalitis lethargica: 100 years after the epidemic". Brain 140.8 (2017): 2246-2251. 
7. Badrfam $\mathrm{R}$ and Zandifar A. "From encephalitis lethargica to COVID-19: Is there another epidemic ahead?" Clinical Neurology and Neurosurgery 196 (2020): 106065.

8. Pilotto A., et al. "The clinical spectrum of encephalitis in COVID-19 disease: the ENCOVID multicentre study". Medrxiv (2020).

9. Zambreanu L., et al. "A case of limbic encephalitis associated with asymptomatic COVID-19 infection". Journal of Neurology, Neurosurgery, and Psychiatry 91.11 (2020): 1229.

10. McAbee GN., et al. "Encephalitis associated with COVID-19 infection in an 11-year-old child". Pediatric Neurology 109 (2020): 94.

11. Ayuso LL., et al. "Bickerstaff encephalitis after COVID-19". Journal of Neurology (2020): 1-3.

12. Panariello A., et al. "Anti-NMDA receptor encephalitis in a psychiatric Covid-19 patient: A case report". rain, Behavior, and Immunity 87 (2020).

13. Monti G., et al. "Anti-NMDA receptor encephalitis presenting as new-onset refractory status epilepticus in COVID-19". Seizure 81 (2020): 18.

14. Pilotto A., et al. "Steroid-responsive encephalitis in Covid-19 disease". Annuals of Neurology 88 (2020): 423-427.

15. Titulaer MJ., et al. "Antibodies to NMDA and other synaptic receptors in choreoathetosis and relapsing symptoms post-Herpes Virus Encephalitis". Movement Disorders Journal - Movement Disorder Society 29.1 (2014): 3.

16. Venâncio P., et al. "Anti-N-methyl-D-aspartate receptor encephalitis with positive serum antithyroid antibodies, IgM antibodies against mycoplasma pneumoniae, and human herpesvirus 7 PCR in the CSF". The Pediatric Infectious Disease Journal 33.8 (2014): 882-883.

17. Linnoila JJ., et al. "CSF herpes virus and autoantibody profiles in the evaluation of encephalitis". Neurology: Neuroimmunology and Neuroinflammation 3.4 (2016).
18. Andersson T., et al. "NMDA-receptor antagonist prevents measles virus-induced neurodegeneration". European Journal of Neuroscience 3.1 (1991): 66-71.

19. Zambrano A., et al. "Neuronal cytoskeletal dynamic modification and neurodegeneration induced by infection with herpes simplex virus type 1". Journal of Alzheimer's Disease: JAD 14.3 (2008): 259-269.

20. Zhou L., et al. "Viruses and neurodegeneration". Virology Journal 10.1 (2013): 172.

21. Huang J., et al. "Potential of SARS-CoV-2 to cause CNS infection: biologic fundamental and clinical experience". Frontiers in Neurology 11 (2020): 659.

\section{Assets from publication with us}

- Prompt Acknowledgement after receiving the article

- Thorough Double blinded peer review

- Rapid Publication

- Issue of Publication Certificate

- High visibility of your Published work

Website: www.actascientific.com/

Submit Article: www.actascientific.com/submission.php

Email us: editor@actascientific.com

Contact us: +919182824667 